\title{
MEASURE: SISTEMA DE COLETA DE INFORMAÇÕES PARA INVENTÁRIO FLORESTAL
}

\author{
Claudiomiro Fernandes Dias Júnior ${ }^{*}{ }^{*}$, Cristiano Bertolini ${ }^{2}$, Rafaelo Balbinot $^{3}$, Sidnei Renato Silveira ${ }^{2}$ \\ ${ }^{1}$ Curso de Bacharelado em Sistemas de Informação, UFSM - Universidade Federal de Santa Maria, \\ CEP 98400-000, Frederico Westphalen/RS, Brasil. \\ 2 Departamento de Tecnologia da Informação, UFSM - Universidade Federal de Santa Maria, \\ CEP 98400-000, Frederico Westphalen/RS, Brasil. \\ ${ }^{3}$ Departamento de Engenharia Florestal, UFSM - Universidade Federal de Santa Maria, \\ CEP 98400-000, Frederico Westphalen/RS, Brasil.
}

*E-mail: juniordiaz489@hotmail.com

\section{RESUMO}

Atualmente, o inventário florestal do levantamento das árvores de uma determinada área é realizado de forma manual, ou seja, o engenheiro florestal precisa anotar em fichas de papel todos os dados levantados. Isso pode gerar alguns problemas, por exemplo: as fichas em papel são vulneráveis à ação do tempo e no próprio manuseio no local da coleta, além da letra ilegível nos registros e no tempo decorrido na digitação dos dados. Visando sanar alguns desses problemas, este trabalho apresenta o resultado da proposta de um sistema que ajuda a realizar o inventário florestal, onde o engenheiro florestal registra os dados da floresta e quando estiver conectado a uma rede, o aplicativo transfere os dados para um servidor. Assim, é possível exportá-los para uma ferramenta de análise, facilitando a realização do inventário florestal e diminuindo as possibilidades de erro. O protótipo foi desenvolvido em colaboração com um grupo de pesquisa da área de Engenharia Florestal, que desenvolve pesquisas na produção de látex e madeira em uma fazenda com plantação de pinus. Os integrantes deste grupo realizam inventários florestais como base de cálculo de estimativas de produção. Antes do desenvolvimento do protótipo aqui apresentado, o processo de inventário era realizado todo manualmente, com as informações sendo registradas em planilhas. Sendo assim, o processo de desenvolvimento de software aplicado foi interativo, utilizando-se técnicas de prototipação, baseando-se em reuniões entre os desenvolvedores e o grupo de pesquisa. Durante as reuniões a equipe elucidava dúvidas e, a partir de pequenos protótipos, definiam as funcionalidades do software, que foi sendo refinado a cada reunião.

Palavras-chave: Inventário florestal. Engenheiro florestal. Aplicativo mobile para inventário florestal.

\section{Introdução}

O inventário florestal qualifica e quantifica recursos referentes às espécies vegetais ocorrentes, especialmente as árvores lenhosas. Os inventários florestais fornecem subsídios necessários para o planejamento das atividades de exploração, manejo, espécies a explorar, intensidades e ciclo de corte. $\mathrm{O}$ inventário também pode ter o propósito de determinar o estoque de madeira existente para fins de planejamento da exploração para o uso sustentável [1].

O inventário florestal fornece as informações de ordem técnica, baseadas nas técnicas de amostragem. Os métodos usados para inventariar populações florestais buscam o menor erro, para uma mesma quantidade de trabalho, fixada a precisão desejada para as informações a serem levantadas e que, posteriormente, serão usadas no planejamento da empresa [2].

Atualmente, o processo de cadastro do inventário florestal em florestas é feito manualmente, utilizando-se de formulários impressos. Desta forma, alguém (por exemplo, um engenheiro florestal) precisa anotar todos os dados, tais como: latitude, longitude, data de medicação, número da equipe, espécie e distrito. Logo após, é necessária a digitação dos dados levantados em uma planilha eletrônica, para posterior análise dos mesmos.

O processo de cadastro, por ser manual, tem como aspectos limitadores: a característica do registro que é atualmente feito em papel, que é vulnerável à ação do tempo e no próprio manuseio no local da coleta, além da letra ilegível 
em alguns registros. Observa-se também, que é preciso de tempo para a digitação dos dados coletados e ainda podem ocorrer erros de digitação, cometidos pelo responsável.

A automação da coleta de dados para a realização do inventário florestal representa um avanço na questão de qualificação dos dados, pois esta é menos propensa a erros e evita o retrabalho causado pela digitação manual. Esta automação auxilia também na construção de uma base de dados consistente e coesa, com dados precisos para o processamento.

Neste contexto, este trabalho apresenta um Sistema de Informação para a coleta de dados florestais, intitulado "MEASURE". Esse sistema é composto por um aplicativo mobile que permite que os dados coletados em campo sejam sincronizados com uma página web e que os mesmos sejam exportados para formatos que possam ser analisados por ferramentas estatísticas.

Sendo assim, este artigo está organizado da seguinte forma: a seção 2 apresenta os trabalhos relacionados; a seção 3 apresenta o referencial teórico sobre o inventário florestal e o desenvolvimento do aplicativo mobile; a seção 4 apresenta o sistema de informação desenvolvido. Finalizando o artigo, são apresentadas as considerações finais e as referências empregadas.

\section{Trabalhos Relacionados}

O trabalho [3] apresenta uma proposta de desenvolvimento de um software dedicado a UMAS (Unidade Móvel de Amostragem do Solo), cujas principais funções são realizar a aquisição, processamento e armazenamento dos dados provenientes de sensores analógicos (célula de carga e potenciômetro) e receptores GNSS (Global Navigation Satellite System). É desenvolvido com a linguagem de programação Microsoft Visual Basic 2010. A execução do software ocorreu em um computador industrial portátil fabricado pela KEE Technologies Powering Farm Production, modelo ZYNX V 2.0 Para realizar a conversão dos dados analógicos para dados digitais, foi utilizado um conversor analógico/digital de baixo custo. A nossa proposta difere da apresentada por [3], já que o nosso aplicativo foi desenvolvido utilizando a linguagem de programação JavaScript, com a execução em dispositivos móveis, como smartphones e tablets. Os dados coletados ficam disponíveis em um banco de dados on-line apresentando, assim, algumas vantagens: 1) sistema online, com site para visualizar os cadastrados e 2) redução de tempo de coleta de dados.

\section{Referencial Teórico}

O inventário florestal é uma ferramenta utilizada para o monitoramento do estoque de madeira ou biomassa em povoamentos florestais. O conhecimento dos recursos florestais torna a gestão e o manejo mais eficientes, além de determinar o potencial de crescimento de exploração da cadeia florestal [4]. Esse inventário é utilizado, principalmente, em florestas de monoculturas, que é o modelo de exploração do solo com apenas um produto agrícola como, por exemplo, o eucalipto, planta originária da Austrália, que chegou ao Brasil na década de 60 e se mantém em expansão, devido seu uso na indústria de celulose e para obtenção de madeira, para a produção de carvão vegetal e de móveis [5].

Segundo [6], as informações básicas para subsidiar o manejo e o planejamento da produção florestal são obtidas a partir do inventário florestal. Os dados desses inventários são obtidos por meio de medições a campo ou de recursos como fotografias aéreas, imagens de satélites entre outras.

\subsection{Inventário Florestal}

O inventário florestal visa obter o máximo de informações de uma floresta com a máxima precisão e o mínimo custo. Esses três fatores desempenham papel importante no planejamento de um inventário florestal e estão diretamente ligados ao tamanho da parcela e, consequentemente, à intensidade de amostragem [7].

Para se estabelecer o tamanho de uma parcela, que pode ser um elemento ou um indivíduo (como uma árvore) ou unidade de medida (como 1 hectare), o tamanho de uma determinada população e de quaisquer de suas subdivisões devem ser mensuráveis [8].

O objetivo do planejamento em um levantamento florestal é coletar observações suficientes para obter a precisão desejada, nem mais e nem menos. O número de observações necessárias depende da precisão desejada e da variabilidade inerente da população que está sendo amostrada.

A Figura 1 apresenta o local em que será realizado o inventário, como exemplo uma fazenda, sendo os talhões representados por meio de um quadrado. Dentro de cada talhão encontram-se as parcelas, que estão representadas por pontos, com tamanho e altura definidas pelo técnico. Essas marcações são feitas com bambu delimitando o espaço de cada parcela para facilitar o corte, quando as árvores chegarem ao tamanho ideal para serem comercializadas. 
Entende-se como talhão a divisão elementar da floresta para a sua administração, tratando-se de uma unidade territorial de planejamento e de seguimento da gestão, sendo utilizado como quadro de referência geográfica. Os talhões são identificados por meio de numeração em algarismos arábicos.

A parcela está dentro do talhão, sendo definida no momento da medição, delimitando o espaço onde as árvores irão ser medidas. Por exemplo, o técnico define que a parcela será de $80 \mathrm{~m}$ x $50 \mathrm{~m}$ e fará a contagem dentro deste espaço delimitado. Preferencialmente, deve ser a mais homogênea possível, particularmente no que se refere às características do povoamento/formações vegetais e às condições da estação agrícola, como por exemplo o eucalipto, planta originária da Austrália, que chegou ao Brasil na década de 60 e se mantêm em expansão, devido seu uso na indústria de celulose e para obtenção de madeira para produção de carvão vegetal e móveis [6].



Figura 1. Modelo de Local, Talhão, Parcela e Árvores

\subsection{Desenvolvimento Mobile}

Este artigo apresenta o desenvolvimento de um aplicativo independente de plataforma (mobile ou web) utilizando as tecnologias Ionic, Angular e Firebase. O Ionic é um framework multiplataforma de código aberto, que permite desenvolver aplicativos móveis para todas as plataformas com apenas um conjunto de linguagens: JavaScript, HTML
(HyperText Markup Language) e CSS (Cascading Style Sheets) [9].

O Angular é um framework JavaScript MVC (ModelView-Controller) para web, que tem o objetivo de trazer grande parte das ferramentas e capacidades que são codificadas no lado servidor para o lado cliente. Com isso, o desenvolvimento, os testes e a manutenção dos sistemas são facilitados. O Angular permite também a extensão do HTML prestando as funcionalidades por meio de elementos personalizados, atributos, classes e comentários [10].

O Firebase é um banco de dados não-relacional, não possuindo relacionamento de chaves primárias e estrangeiras como em outros SGBD (sistema de gerenciamento de banco de dados). De acordo com [11], o Firebase é indicado para flexibilizar o backend com boas práticas, diminuindo o tempo de desenvolvimento e evita que o servidor seja sobrecarregado de informações. Possui o benefício da nuvem, não necessita instalação e os dados são protegidos, pois o Firebase utiliza SSL (Secure Sockets Layer) para encriptação.

\section{Sistema de Coleta de Dados Florestais}

O aplicativo mobile pretende apoiar engenheiros florestais na coleta de dados para o inventário florestal, por meio da automatização da coleta de dados, facilitando o registro de cada árvore. Os registros serão enviados de forma automática para um banco de dados. As principais funcionalidades do aplicativo mobile são:

- disponibiliza o acesso aos cadastros das árvores;

- permite editar, cadastrar e listar na própria tela em que está sendo realizado o cadastro das árvores, que pertencem ao talhão da parcela da fazenda ou floresta escolhida;

- permite realizar as operações de edição e cadastro de árvores, talhões e parcelas, de forma on-line e off-line, sem perda de desempenho;

- realiza a sincronização dos cadastros das parcelas existentes no dispositivo mobile, para o banco de dados que estará hospedado nos servidores da Google [12].

Os requisitos de sistema que foram definidos para o aplicativo compreendem:

- Ambiente de desenvolvimento Visual Studio Code, que consiste em uma IDE (Integrated Development Environment) para desenvolvimento de software;

- Banco de dados Firebase, utilizado para armazenar as informações da coleta dos dados; 
- O framework Angular, que permite desenvolver, reusar os códigos para construir aplicativos para web, mobile e desktop, e também possui um bom desempenho em renderizar páginas web, além de existirem muitos programadores que contribuem para melhorias do framework ao redor do mundo [13].

A Figura 2 apresenta o diagrama de casos de uso da solução desenvolvida, baseado na UML (Unified Modeling Language). O aplicativo permite ao engenheiro florestal cadastrar local, parcela e talhão em um único cadastro, e o cadastro das árvores permite o registro das medidas das árvores. O registro de qualquer dado, caso possua algo de errado, também pode ser editado pelo próprio operador do sistema.

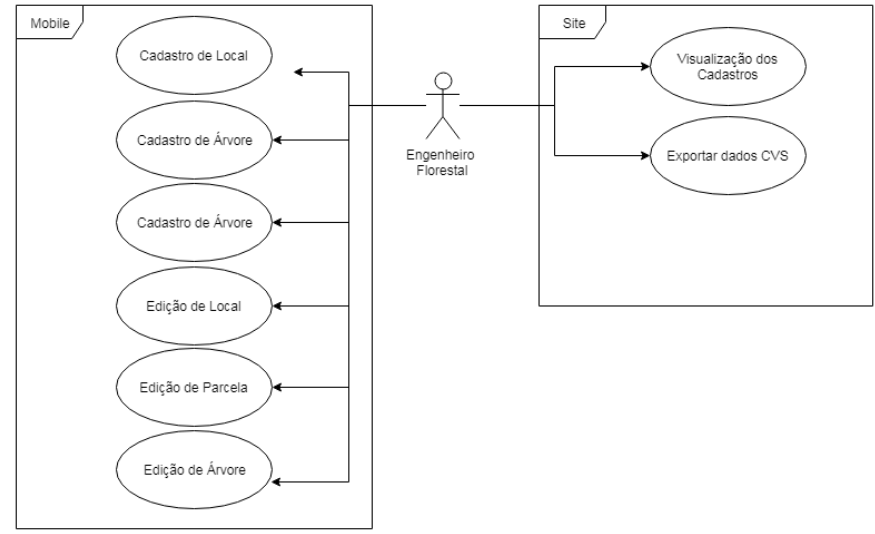

Figura 2. Diagrama de Casos de Uso da aplicação (Fonte: Os autores, 2019)

Além do aplicativo mobile, o sistema possui um módulo web que permite que o engenheiro florestal consiga visualizar os dados gerados por outros engenheiros. Também é possível fazer o download do banco de dados no formato CSV (Comma Separated Values) para importação dos dados em sistemas de terceiros.

A Figura 3 apresenta o fluxo de comunicação da aplicação. O banco de dados Firebase é encarregado por gerenciar os pedidos para gravar, editar e excluir os dados por meio de chamadas de requisições que são geradas pelo aplicativo mobile. Então, como resposta, o banco de dados envia sua resposta permitindo que altere, salve, exclua ou faça a leitura de dados anteriormente salvos. A solução consiste em duas partes: 1) a parte mobile, responsável pela coleta das informações e 2) a parte web, onde é possível realizar a leitura das informações quando é realizada a sincronização entre as duas partes do sistema.

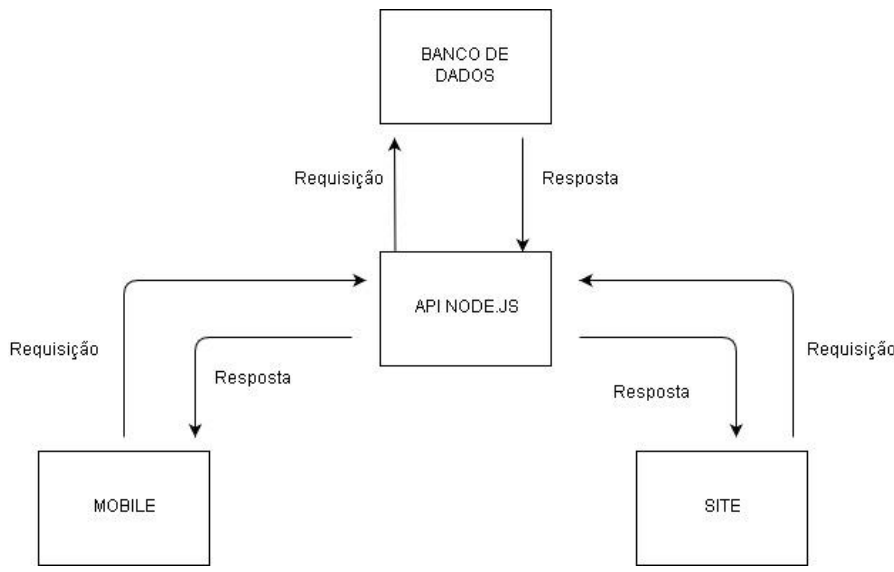

Figura 3. Modelo de comunicação da solução desenvolvida. (Fonte: Os autores, 2019)

O modelo de dados é dividido em três partes: 1) as coleções (recipiente ou uma pasta); 2) os documentos, que são os dados obtidos por meio do aplicativo mobile e 3) a subcoleção, que é associada a um documento dentro de uma coleção, que tem como função guardar informações referentes àquele documento (isto é mais indicado quando se possui um banco de dados mais complexo) [12]. A Figura 4 apresenta o modelo de dados.

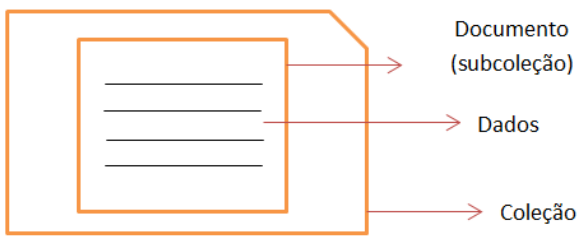

Figura 4. Banco de Dados (Fonte: Os autores, 2019)

A Figura 5 apresenta o diagrama de sequência para realizar o cadastro dos dados no aplicativo mobile. Neste cadastro o engenheiro florestal precisa realizar o cadastro do local, parcela e das árvores e sinalizar que o cadastro foi efetuado:

- Cadastrar Local: possibilita ao engenheiro florestal cadastrar a fazenda ou floresta em que está realizando a coleta com um equipamento de precisão de geolocalização e, após definir as coordenadas geográficas, define um código para o local e a equipe, nomeando-a, para facilitar a sua localização e organização do processo;

- Cadastrar Parcela: possibilita fazer o cadastro da parcela a ser medida junto ao talhão, que é um conjunto de parcelas. Em seguida, deve selecionar o 
local ou fazenda em que está sendo realizada a coleta das informações;

- Cadastro das Árvores: após todos os cadastros anteriores serem realizados, ficam disponíveis os campos referentes aos códigos da fazenda e da parcela. $\mathrm{O}$ engenheiro deve escolher como irá medir: se pelo DAP (diâmetro à altura do peito) ou por meio do CAP (circunferência à altura do peito). Será adicionado o dado na $\mathrm{H}$. total e o código da árvore na categoria que melhor se enquadrar;

- Cadastro Efetuado: Após o cadastro de cada informação é enviado primeiro ao banco de dados offline do Firebase no smartphone e, ao conectar à Internet, este é automaticamente sincronizado com o banco de dados Firebase na nuvem, disponibilizando os dados para o site.


Figura 5. Diagrama de sequência cadastro no aplicativo (Fonte: Os autores, 2019)

A Figura 6 apresenta o diagrama de sequência para realizar a edição dos dados que precisam ser alterados no momento em que o usuário está medindo as árvores.



Figura 6. Diagrama de sequência de edição de dados (Fonte: Os autores, 2019)

O módulo web do Sistema Measure apresenta, na sua tela inicial (Figura 7), os dados anteriormente sincronizados por meio do aplicativo mobile. As informações apresentadas no módulo web podem ser exportadas para o formato CSV, por meio do botão "exportar arquivo", que gera o arquivo para salvar no computador. Esse arquivo é necessário para ser usado em um software de terceiros de análise de dados, dispensando a transcrição de todos os dados para o software de análise.

A Figura 8 apresenta um exemplo de arquivo, no formato CSV, que foi exportado pelo sistema desenvolvido e aberto em um software de planilha eletrônica. Além dos campos obrigatórios, possui informações sobre o engenheiro responsável.

\begin{tabular}{|c|c|c|c|c|c|c|c|}
\hline FAZENDA & TALHÃO & UA & Código & DAP & CAP & H.TOTAL & ENGENHEIRO \\
\hline 1 & & 3 & 0 & & 12 & 45,00 & Joắ da Silva \\
\hline 2 & 2 & 1 & 0 & & 16,0 & 12,1 & Mateus \\
\hline 2 & 1 & 1 & 0 & 15,00 & & 12,1 & Guilherme \\
\hline 2 & 2 & 2 & 1 & 15,00 & & 12,1 & Maria \\
\hline 2 & 2 & 2 & 1 & 14,00 & & 7.8 & Julia \\
\hline 2 & 1 & 1 & 3 & & 7,8 & 12,1 & Alberto \\
\hline 2 & 1 & 1 & 2 & 14,00 & & 11,4 & Giovana \\
\hline
\end{tabular}






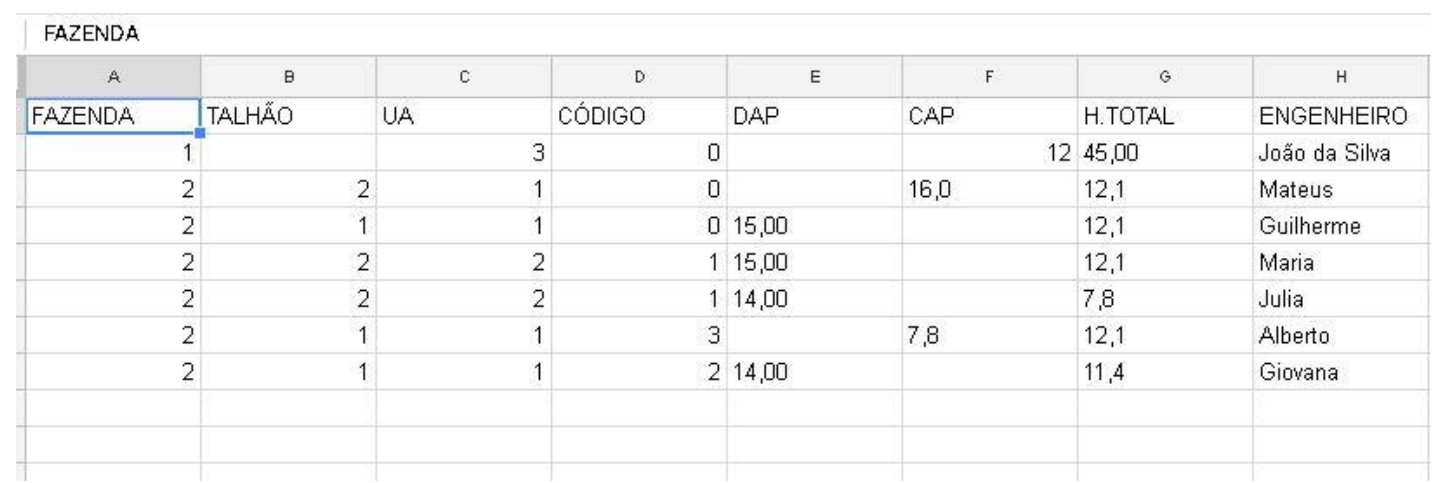

Figura 8. Exemplo de Arquivo no Formato CSV exportado pelo sistema (Fonte: Os autores, 2019)

A Figura 9 apresenta os ícones iniciais para o cadastro, que começa por meio do local, parcela e, por fim, o cadastro das árvores.

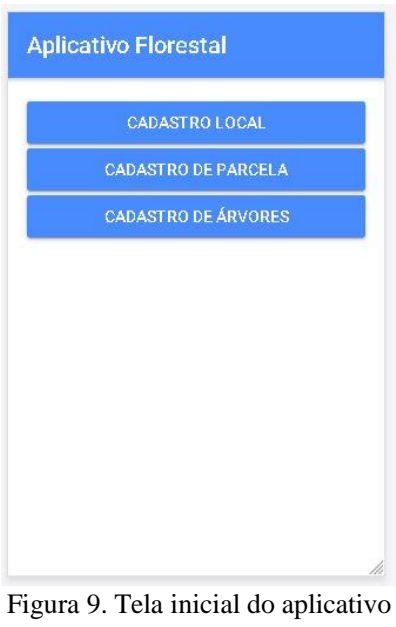

(Fonte: Os autores, 2019)

A Figura 10 apresenta um exemplo de planilha impressa que é usada de forma manual para realizar o inventário florestal. Este documento pode ser rasurado, molhado ou ficar com os dados cadastrados de forma ilegível. Esses dados são recolhidos no momento em que a equipe está fazendo a medição e a contagem daquela parcela de árvores.

A Figura 11 apresenta o cadastro do local, o qual apresentará similaridades com os campos da planilha manual usada até o momento. O campo código do projeto é um identificador do cadastro. Os campos: latitude, longitude e coordenadas UTM terão seus dados oriundos de um equipamento de precisão que fornecerá as coordenadas corretas. O campo distrito determinará o lugar em que o inventário será realizado.

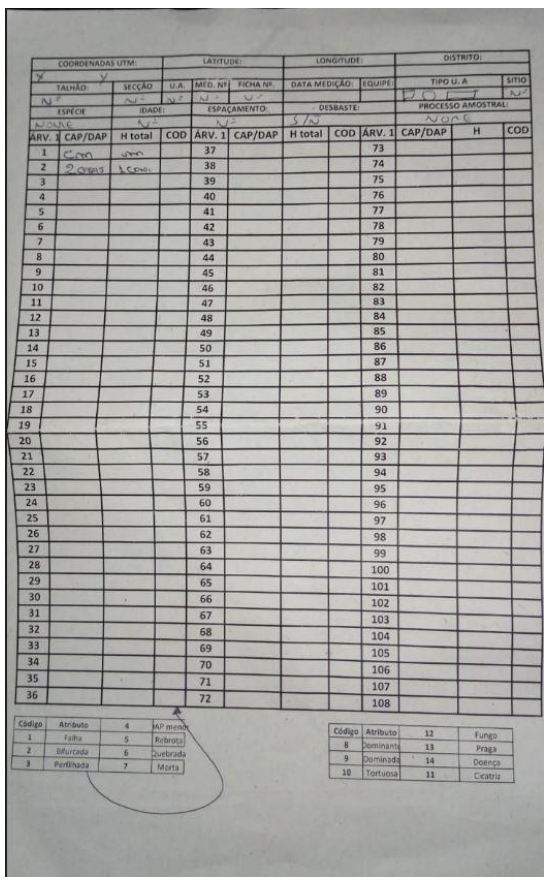

Figura 10. Exemplo de Planilha para Inventário Manual (Fonte: Os autores, 2019)

O campo data da medição refere-se ao dia que a equipe irá realizar a medição, e o campo equipe armazena o código ao qual o grupo pertence. O campo sítio apresenta o número do índice da qualidade do solo ou crescimento.

A Figura 12 apresenta o cadastro do número inicial da parcela, referente ao número do talhão, que será também cadastrado, referente ao que está sendo medido naquele momento e à espécie de árvore que está sendo analisada. No campo código da fazenda é adicionado o código do local anteriormente cadastrado. 


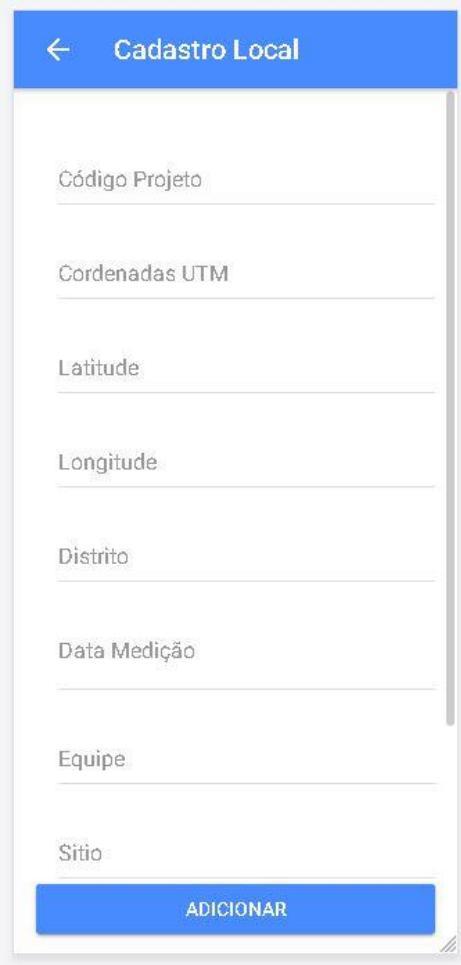

Figura 11. Cadastro do Local (Fonte: Os autores, 2019)



Figura 12. Cadastro da Parcela e Talhão (Fonte: Os autores, 2019)
A Figura 13 apresenta a tela de cadastro de árvores. No início do cadastro é inserido qual o nome do engenheiro que está efetuando o cadastro. $\mathrm{O}$ engenheiro decidirá qual o código da fazenda, parcela e talhão, além de uma das formas de medição: DAP ou CAP. O DAP, em valores comerciais, representa $1,30 \mathrm{~m}$ de altura, ou medição da circunferência (CAP), por meio de uma fita métrica.

O campo código da fazenda é utilizado para definir em qual fazenda está sendo realizado o inventário florestal. O campo código da parcela define qual parcela se está medindo em referência ao cadastro anterior, $\mathrm{O}$ campo $H$ total apresenta o tamanho de cada árvore. O campo código é o atributo que corresponde às características da árvore, tais como: se é falhada, bifurcada, etc. Caso for salvo como "vazio" o valor será zero, que não pertence a nenhum outro atributo.

O campo U.A se refere a qual parcela aquela árvore pertence, pois já está vinculada a um talhão. Ao finalizar o cadastro de todas as árvores da parcela, o usuário irá clicar no botão finalizar cadastro.

\section{Cadastro de Arvore}

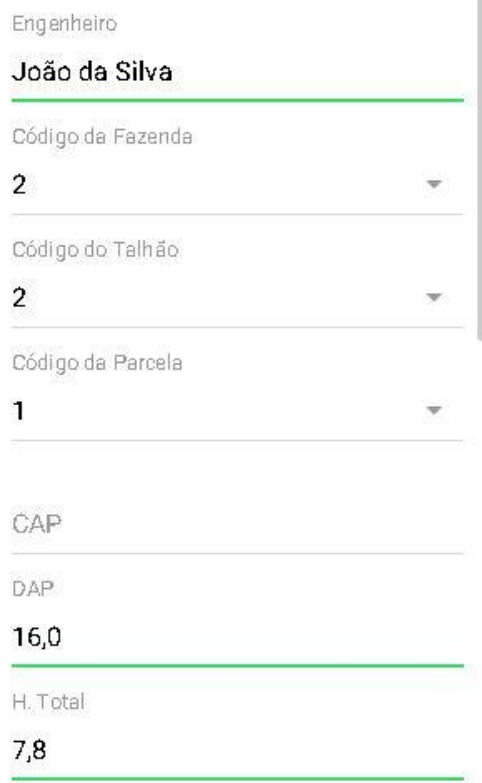

Código



Figura 13. Cadastro dos tamanhos das árvores 


\section{Considerações Finais}

Este artigo apresentou o aplicativo "Measure", permitindo a coleta de dados, facilitando e simplificando a realização do inventário florestal, por meio das ferramentas e bancos de dados, empregando as tecnologias Angular, Ionic e Firebase.

O uso de um aplicativo mobile representa um avanço na qualidade dos dados coletados e na confiabilidade dos mesmos, pois permite um cadastro mais eficiente de novas parcelas de talhão, além de fornecer uma sincronização em tempo real.

O aplicativo desenvolvido mostrou-se como uma proposta eficiente para a realização do inventário florestal, pois além das vantagens de excluir a possibilidade de erros de digitação e de perda de dados, pode ser utilizado simultaneamente por vários engenheiros ou técnicos, agilizando o processo e garantindo a uniformidade dos dados. Estas informações são baseadas nos testes realizados, pelo grupo de pesquisa, com a aplicação do protótipo desenvolvido.

Além disso, permite a exportação dos dados do site, no formato CSV, possibilitando a importação e a análise no programa escolhido pelo usuário, permitindo também que estes dados sejam enviados de forma on-line, tornando desnecessário o deslocamento do engenheiro ou técnico até o local de digitação dos dados.

A proposta de trabalhos futuros envolve o aprimoramento do site, para que este permita a gestão dos dados pelo usuário. A gestão se dará por implementação de funções que permitam que os envolvidos na coleta de dados, possam acessar e acompanhar o andamento do inventário florestal e realizar avaliações e implementações que possam aperfeiçoar a coleta. No aplicativo mobile poderá ser implementada a opção de realizar um login próprio para cada engenheiro ou técnico; registrar imagens das árvores caso seja necessário, e usar os códigos da latitude e longitude armazenados no banco de dados, para mostrar em um mapa interativo tanto no aplicativo mobile quanto no módulo web.

\section{MEASURE: FOREST INVENTORY SYSTEM APPLICATION}

ABSTRACT: Currently, the forest inventory, which collects the information about trees, is realized manually. In this way, the forest engineer has to take notes in paper sheets all collected data, which can be a problem like the paper sheets are vulnerable to the weather and the way they are manipulated inside the forest; also some records can be eligible or transferred to the computer in a wrong way. This paper presents a proposal of a forest inventory system application, where the forest engineer records the collected data about the forest in the field, and when the app connects to a network it transfers the data to a server. Thus, it is possible to export the data to an analysis tool, which makes the forest inventory easy to be done and less error-prone.

Keywords: Forest inventory. Forest engineer. Forest inventory system application

\section{Referências}

[1] CESARO, A.; ENGEL, O. A. C. (1994). Comparação dos Métodos de Amostragem de área Fixa, Relascopia e de Seis Árvores quanto à Eficiência, no Inventário Florestal de um Povoamento de Pinus. Ciência Florestal, v. 4, n. 1. Disponível em: https://periodicos.ufsm.br/cienciaflorestal/article/view/300. Acesso em nov. 2018.

[2] JOAQUIM, M. S. (2009). Carvão Vegetal: uma alternativa para os produtos rurais do sudoeste goiano. Repositório Institucional da UnB. Disponível em: http://repositorio.unb.br/handle/10482/6330. Acesso em nov. 2018.

[3] SILVA LIMA, N. (2018). Amostras Virtuais no Monitoramento da Produção Florestal. Repositório Institucional UNESP. Disponível em: https://repositorio.unesp.br/handle/11449/153248. Acesso em mar. 2019.

[4] ANGULAR.IO. (2019). Angular: One Framework Mobile \& Desktop. Disponível em: https://angular.io/. Acesso em out. 2019

[5] NASCIMENTO JÚNIOR; BONETT, T. P. (2016) Desenvolvimento de Aplicações Multiplataforma para Dispositivos Móveis utilizando Ionic e Phonegap. Semana de Informática de Paranavaí. Disponível em: http://web.unipar.br/ seinpar/2016/publicacao/Luiz_Carlos_Junior.pdf. Acesso em set., 2018

[6] KUMAR, K. N. M et al. (2016) Implementing Smart Home using Firebase. International Journal of Research in Engineering and Applied Sciences (IJREAS). Disponível em: http://euroasiapub.org/wpcontent/uploads/2016/11/16EASOct-4186.pdf. Acesso em out. 2018.

[7] FREESE, F. (1967). Elementary Statistical Methods for Foresters. Agriculture Handbook. U.S. Dept. of Agriculture, Forest Service. Disponível em: https://www.fpl.fs.fed.us/documnts/usda/ah317.pdf. Acesso em out. 2018

[8] NAKAJIMA, N. Y.; NETTO, S. P.; DRUSZCZ et al. (2011).

Comparação da Precisão entre os Métodos de Amostragem Linha e Parcela Circular Concêntrica em Povoamentos de Pinus Elliottii. Revista Acadêmica: Ciência Animal, v. 9, n. 2. Disponível em: https://periodicos.pucpr.br/index.php/cienciaanimal/article/view/11750. Acesso em out. 2018.

[9] GOOGLE DEVELOPERS. (2019). Firebase. Disponível em: https://firebase.google.com/?hl=pt-BR. Acesso em out. 2018.

[10] CAMPOS, F. H.; PADOVANI, C. R. (2013). Aplicativo para Aquisição, Processamento e Armazenamento de Dados de Receptores GNSS e Sensores Analógicos. Tekhne e Logos, v.4, n.1. Disponível em: http://www.fatecbt.edu.br/seer/index.php/tl/article/view/166. Acesso em nov. 2018 
10

[11] BORTOLI, N. S.; RUFINO, R. R. (2017) Conceito para o Desenvolvimento Web utilizando Spring Boot, Bootstrap e Angular.js. Disponível em: http://docplayer.com.br/41679489-Conceito-para-o-desenvolvimento-webutilizando-spring-boot-bootstrap-e-angular-js.html. Acesso em out. 2018.

[12] FAO, R. (1974). Manual de Inventario Florestal: con especial referencia a los bosques mixtos tropicales. Disponível em: http://agris.fao.org/agrissearch/search.do?recordID=XF2017001601. Acesso em nov., 2018.

[13] ARAUJO, H. J. B. d. (2006). Inventário Florestal a 100\% em Pequenas Áreas sob Manejo Florestal Madeireiro. Acta Amazônica, v. 36, p. 447-464. Disponível em: http://www.scielo.br/pdf/aa/v36n4/v36n4a07. Acesso em mar. 2019. 